\title{
Micro-Macro Simulation Technique Combined with Multilevel Damage Assessment Methodology for RC Building Structures
}

\author{
Jianguang Yue \\ College of Civil Engineering, Nanjing Tech University, Nanjing 211800, China \\ Correspondence should be addressed to Jianguang Yue; jgyue@njtech.edu.cn
}

Received 14 March 2015; Revised 16 August 2015; Accepted 18 August 2015

Academic Editor: Antônio G. B. de Lima

Copyright (C) 2015 Jianguang Yue. This is an open access article distributed under the Creative Commons Attribution License, which permits unrestricted use, distribution, and reproduction in any medium, provided the original work is properly cited.

\begin{abstract}
In order to assess the inherent damage mechanism of reinforced concrete (RC) structures, a micro-macro simulation technique combined with multilevel damage assessment methodology is presented. An element-coupling model is developed by combining mixed dimensional finite elements with the aid of multipoint constraint equations, which could be achieved from the energy conservation principle. Thus, the micro-scale damage details could be obtained in a macro-scale setting of the global structure. Furthermore, using different damage indicators, a generalized damage model is combined with the multilevel damage performance to assess the damage evolution. Finally, an in situ lateral loading test of a real RC frame structure was analyzed to verify this proposed damage assessment methodology. The finite element method utilizing the proposed damage model products results in good agreement with those of the tests. It shows that the proposed methodology is a very helpful tool to assess and reveal the inherent damage mechanism of RC structures.
\end{abstract}

\section{Introduction}

Many earthquake disasters indicate that seismic damage of buildings normally begins at material level, develops or cumulates at section level, member level, and storey level, and finally ends at the failure state of structure level. However, it is difficult to monitor or measure the damage behavior of structures subjected to real ground motions as well as during shaking table testing. Since the size and weight of the specimen is restricted by the capacity of the shaking table, the pseudo-dynamic testing to existing structures in site or full-scale structures in the laboratory to acquire realistic data about performance, evolution of damage, and strength deterioration has been widely and successfully employed. A fullscale pseudo-dynamic test of a three-storey, two-by-two bays, irregular reinforced concrete (RC) frame was performed at the European Laboratory for Structural Assessment of the Joint Research Centre of the European Commission [1]. It aimed to study the coupled translational-torsional dynamic response of an irregular multistorey building under bidirectional earthquake loading. Some in situ tests on five existing structures show that ambient vibration measurements constitute a very efficient method to obtain information on the seismic behavior of most existing buildings [2]. On the other hand, an advanced numerical simulation technique is an efficient, inexpensive, widely used way to evaluate the damage behavior of structures. The most usually used method is the finite element method (FEM). The one-dimensional (1D), at macro-scale, FEM based on the fiber-beam-element model [3] is already widely accepted as a suitable method for proper simulation of RC structures. However, it has some difficulties to acquire the damage details at micro-scale. The three-dimensional (3D), at micro-scale, FEM can predict the micro-scale damage details but requires more computational efforts, especially for a global or complex structure. Therefore, the mixed-elements numerical model [4-9] or transitionelement model [10] in FEM is presented to capture the microscale damage at reasonable calculation cost.

The damage data like stiffness, strength, deformation, and energy dissipation from material level to structure level could be represented in damage assessment models. Damage models are defined on the basis of four types of measurements, that is, measurements based on remaining life or residual strength, micro-structural measurements, measurements of physical parameters, and measurements of changes in mechanical behavior. Many proposed damage 
models are defined by mechanical behavior indicators, like deformation, bearing capacity or dynamic characteristics, dissipation hysteretic energy indicators, and the combination of deformation and energy indicators [11, 12]. For example, the plastic dissipation energy of members [13] and the deformation characterized by drift ratio or plastic rotation were used to define damage models $[14,15]$. The widely known Park-Ang damage model [16] is presented by combining both maximum plastic displacement and plastic dissipated energy. However, it cannot evaluate damage at material level and section level. An energy and low-cycle fatiguebased hysteresis damage model has also been developed for deteriorating systems [17]. Taking into account axial forcebending moment, a section-level-based damage model was proposed to assess the damage behavior of steel structures [18]. By integrating multilayered finite elements at a section, a global damage model was constructed from local damage of concrete and reinforcement [19], which depends on the probable collapse mechanism of the structure. In a local/global damage model for RC structures [20], the damage internal variable of the constitutive model was taken as the local damage indicator. This model was further modified by introducing a two-parameter concrete damage constitutive model and taking into account the concrete plastic strain and reinforcement buckling effect [21]. It could be seen that most of the abovementioned damage models are only available for one or a few structural levels which cannot completely assess the multilevel damage evolution.

Another important hand of performance-based design (PBD) relies on the performance-based limit. A seismic performance level is normally determined on the basis of structural member damage states [22, 23]. Provisions and codes for performance assessment of RC structures, such as FEMA356 [24], Eurocode 8 [25], and ASCE/SEI 41 [26], include deformation limits to estimate the performance of members or structures. Basically all deformation-based provisions employ similar damage state definitions for reinforced concrete members. Section chord rotation and material strain limits have also been used to evaluate the performance of structural members. Furthermore, strain limits are defined for concrete and steel at damage limit states as a vital component of PBD. Thus it can be found that there are no performance criteria that could cover all structural levels, that is, material level, section level, member level, storey level, and structure level.

In this work, an element-coupling model, which consisted of mixed dimensional elements coupled by multipoint constraint equation, is presented to capture the microscale damage details and global structure behavior together. A generalized damage model is combined with multilevel performance to assess the damage evolution from material level to structure level. The proposed methodology is verified by the analysis of an in situ lateral loading test of a real RC frame structure.

\section{Micro-Macro-Coupling FEM}

All structures in the real world are three-dimensional, but in ordinary strength of materials, approximations are made to facilitate simple analysis of a problem. In FEM, reduced element types are defined in terms of a reduced geometric representation, with properties that account for the dimensions not included. These element types produce more computationally efficient models, thus reducing analysis costs.

Many structural applications of the finite element method contain long slender regions, thin zones, and complex chunky portions. Long slender regions can be represented appropriately using beam elements, thin zones can usually be modeled using shell elements, and chunky portions are best represented as three-dimensional elements. However, practical models usually contain a mixture of more than one of the above region categories. In order that each region is represented by an appropriate element type, some sort of coupling scheme is required to form a link between the meshes of different types.

Multipoint constraint equations define a relationship between sets of displacements within a finite element model. With the aid of ABAQUS software [27], mixed dimensional elements could be coupled together by the multipoint constraint equations. The normal form is given in the following:

$$
u=\sum_{i=1}^{n} X_{i} u^{\prime},
$$

where $u$ is the nodal freedom of the lower dimension element, $u^{\prime}$ is the higher dimension element, $n$ is the number of higher dimension elements on the interface, and $X_{i}$ is the constraint coefficients of node $i$.

This solution was arrived at by equating the work of the interface stresses in terms of the lower dimension interface rotations and transverse displacements to the work of the boundary stresses on the higher dimension side of the interface, namely, the energy conservation principle here. Coupling is achieved by introducing the assumed variation of the stresses, given by the appropriate beam, plate, or shell theory, over the cross-section of the interface. The coupling can be achieved for arbitrary transitions so long as the stress distribution due to any given load can be determined at each interface.

2.1. $1 D$ and $3 D$ Elements Coupling. According to the energy conservation principle, the work done of the nodal stress of 3D solid elements on the interface should be equal to the work done of the nodal force of the $1 \mathrm{D}$ beam element which is coupled on the interface (see Figure 1). Thus, the relationship of nodal forces of beam element and nodal stresses of solid elements can be obtained as

$$
\begin{aligned}
& F_{i} u_{i, \text { beam }} \\
& \quad= \begin{cases}\int_{A} \sigma_{3 i} u_{i, \text { solid }}^{\prime} d A, & (i=1,2,3) \\
\int_{A} \sigma_{33} u_{3, \text { solid }}^{\prime} d A, & (i=4,5) \\
\int_{A}\left(\sigma_{31} u_{1, \text { solid }}^{\prime}+\sigma_{32} u_{2, \text { solid }}^{\prime}\right) d A, & (i=6),\end{cases}
\end{aligned}
$$

where $A$ is the interface area; $F_{i}$ is the nodal force of beam element along axis $i ; \sigma_{3 i}$ is the nodal stress component of 


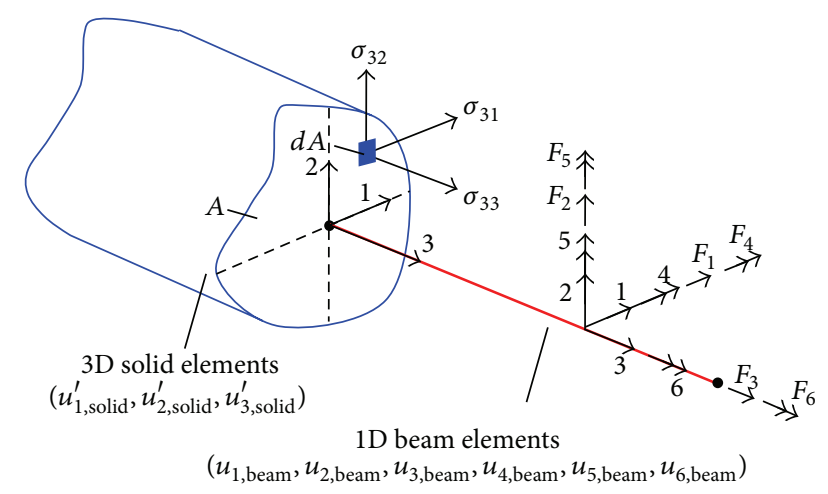

FIGURE 1: Coupling of 1D element with 3D elements.

solid elements on interface along axis $i ; u_{i}$ is the nodal displacement component of beam element connected with interface along axis $i ; u_{i}^{\prime}$ is the nodal displacement component of solid elements on interface along axis $i$.
For thin-walled circular section, the stress on interface can be obtained from the theory of materials mechanics,

$$
\sigma_{3 i}= \begin{cases}\frac{F_{i}}{A}+\frac{6 F_{6}}{b^{2}(3 h-b)}, & (i=1,2) \\ \frac{F_{i}}{A}+\frac{F_{4} y}{I_{1}}+\frac{F_{5} x}{I_{2}}, & (i=3),\end{cases}
$$

where $x$ or $y$ is the nodal coordinates of the solid elements on interface; axis 1 is the $x$ direction and axis 2 is the $y$ direction; the origin point of this coordinate system is located at the beam node on interface; $I_{1}$ and $I_{2}$ are the principal moment of inertia of the interface with respect to axis 1 and axis 2, respectively; $A_{0}$ is the area which is bounded by the middle line of the section wall; $t$ is the thickness of cross-section wall; $R_{0}$ is the average radius of cross section.

By substituting (3) into (2), the multipoint constraint equations can be achieved as

$$
u_{i, \text { beam }}= \begin{cases}\frac{1}{A} \sum_{j=1}^{n} \int_{A_{j}}\left[N_{\text {solid }}\right]\left\{u_{i, \text { solid }}^{\prime}\right\} d A=\left[X_{i}\right]\left[u_{i}^{\prime}\right], & (i=1,2,3) \\ \frac{1}{I_{i-3}} \sum_{j=1}^{n} \int_{A_{j}} y\left[N_{\text {solid }}\right]\left\{u_{3, \text { solid }}^{\prime}\right\} d A=\left[X_{i}\right]\left[u_{i, \text { solid }}^{\prime}\right], & (i=4) \\ \frac{1}{I_{i-3}} \sum_{j=1}^{n} \int_{A_{j}} x\left[N_{\text {solid }}\right]\left\{u_{3, \text { solid }}^{\prime}\right\} d A=\left[X_{i}\right]\left[u_{i, \text { solid }}^{\prime}\right], & (i=5) \\ \frac{6}{b^{2}(3 h-b)} \sum_{j=1}^{n} \int_{A_{j}}\left[N_{\text {solid }}\right]\left(\left\{u_{1}^{\prime}\right\}+\left\{u_{2}^{\prime}\right\}\right) d A=\left[X_{1, i}\right]\left[u_{1, \text { solid }}^{\prime}\right]+\left[X_{2, i}\right]\left[u_{2, \text { solid }}^{\prime}\right], \quad(i=6),\end{cases}
$$

where $A_{i}$ is the element area on the interface; $[N]$ is shape function matrix of solid elements on the interface; $[X]$ is coefficient matrix of multipoint constraint equations; $\left\{u^{\prime}\right\}_{i}$ is nodal freedom matrix of elements $i$ on the interface; $\left[u^{\prime}\right]$ is the nodal freedom matrix on the interface.

2.2. $1 D$ and $2 D$ Elements Coupling. Figure 2 shows the coupling interface of one-dimensional (1D) beam elements and two-dimensional (2D) shell elements. In this figure, $u_{i \text {,beam }}$ and $u_{i \text {,shell }}$ are the nodal displacement components of beam element and shell elements, respectively, on the interface along the axis $i$. According to the energy conservation principle, the work done of the nodal stress of shell elements should be equal to the work done of the nodal force of beam element on interface. Then, the relationship of nodal forces of beam element and nodal stresses of shell elements can be achieved as

$$
F_{i} u_{i, \text { beam }}= \begin{cases}\int_{A} \sigma_{3 i, \text { shell }} u_{i, \text { shell }} d A, & (i=1,2,3) \\ \int_{A} \sigma_{33, \text { shell }} u_{3, \text { shell }} d A+\int_{S} M_{s x} u_{4, \text { shell }} d s+\int_{S} M_{s y} u_{5, \text { shell }} d s, & (i=4,5) \\ \int_{A}\left(\sigma_{31, \text { shell }} u_{1, \text { shell }}+\sigma_{32, \text { shell }} u_{2, \text { shell }}\right) d A, & (i=6),\end{cases}
$$

where $A$ is the interface area; $F_{i}$ is the nodal force of beam element along the axis $i ; \sigma_{3 i \text {,shell }}$ is the nodal stress component of shell element on interface along axis $i ; u_{i \text { shell }}$ is the nodal displacement component of shell elements on interface along 


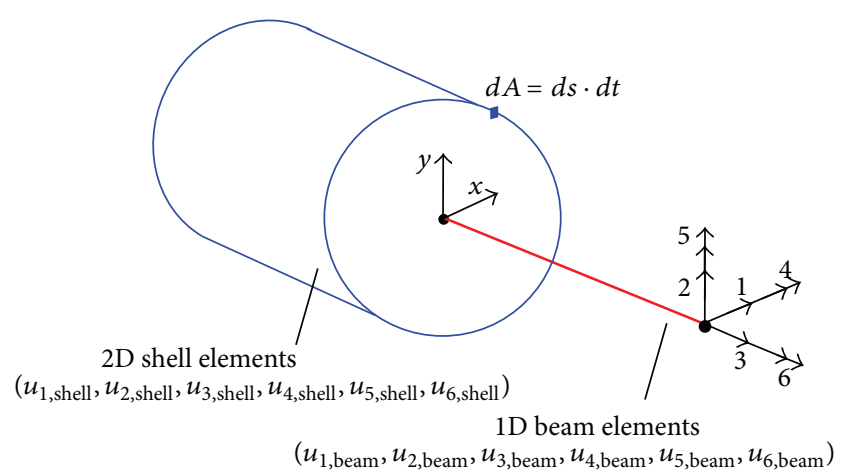

FIgURE 2: Coupling of 1D element with 2D elements.

axis $i ; M_{s x}$ and $M_{s y}$ are additional bending moment on the interface along axes $x$ and $y$, respectively, induced by the nonuniform stress of shell elements.

In (5), the solution method of the multipoint constraint equations about $u_{1 \text {,beam }}, u_{2 \text {, beam }}$, and $u_{6 \text {,beam }}$ is the same as the method for (4). Thus, the multipoint constraint equations corresponding to $u_{3, \text { beam }}, u_{4 \text {,beam }}$, and $u_{5 \text {,beam }}$ are summarized as follows. By substituting the simplified form of stress $\sigma_{33 \text {,shell }}=F_{3} / A$ into (5), the multipoint constraint equation for $u_{3, \text { beam }}$ can be given as

$$
\begin{aligned}
u_{3, \text { beam }} & =\frac{1}{A} \sum_{i}^{n} \int_{A_{i}}\left[N_{\text {shell }}\right] d A\left\{u_{3, \text { shell }}\right\} \\
& =\left[X_{3}\right]\left[u_{3, \text { shell }}\right] .
\end{aligned}
$$

According to the energy conservation principle, the work done of the nodal stress of shell elements should be equal to the work done of the nodal force $F_{4}$ of the beam element. Taking into account the work done of the additional bending moment $M_{s}$, the relationship of nodal forces of beam element and nodal stresses of shell elements can be expressed as

$$
\begin{aligned}
F_{4} u_{4, \text { beam }}= & \int_{A} \sigma_{33} u_{3, \text { shell }} d A+\int_{S} M_{s x} u_{4, \text { shell }} d s \\
& +\int_{S} M_{s y} u_{5, \text { shell }} d s, \\
\sigma_{33}= & F_{4}\left(\frac{I_{12}}{I_{12}^{2}-I_{1} I_{2}} x+\frac{I_{2}}{I_{1} I_{2}-I_{12}^{2}} y\right), \\
M_{s x}= & \int_{-t / 2}^{t / 2} \sigma_{33} y d y\left(\frac{d x}{d s}\right) \\
= & 2 \int_{0}^{t / 2} F_{4}\left(\frac{I_{2}}{I_{1} I_{2}-I_{12}^{2}} y\right) y\left(\frac{d x}{d s}\right) \\
= & \frac{t^{3}}{12} F_{4}\left(\frac{I_{2}}{I_{1} I_{2}-I_{12}^{2}}\right)\left(\frac{d x}{d s}\right), \\
M_{s y}= & \int_{-t / 2}^{t / 2} \sigma_{33} x d x\left(\frac{d y}{d s}\right) \\
= & 2 \int_{0}^{t / 2} F_{4}\left(\frac{I_{12}}{I_{12}^{2}-I_{1} I_{2}} x\right) x\left(\frac{d y}{d s}\right) \\
= & \frac{t^{3}}{12} F_{4}\left(\frac{I_{12}}{I_{12}^{2}-I_{1} I_{2}}\right)\left(\frac{d y}{d s}\right),
\end{aligned}
$$

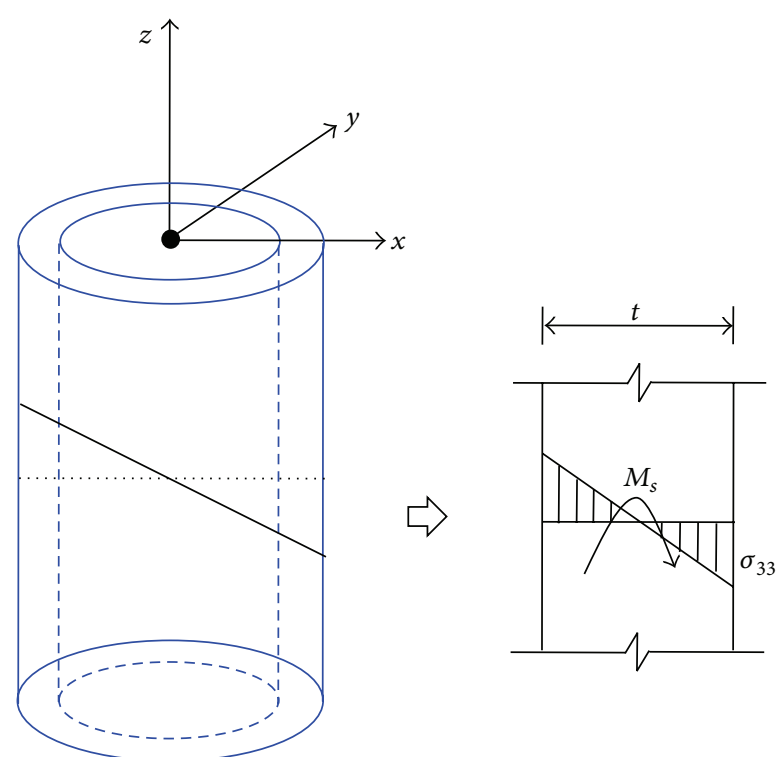

FIGURE 3: Bending moment of shell elements.

where $M_{s}$ is the bending moment in unit length induced by the normal stresses along the thickness $t$ (see Figure 3 ) of shell elements; $M_{s x}$ and $M_{s y}$ are the component of $M_{s}$ on the interface along axes $x$ and $y$, respectively; $I_{12}$ is the product of inertia for axis 1 and axis 2 .

From (7), the multipoint constraint equation for $u_{4 \text {,beam }}$ can be expressed as

$$
\begin{gathered}
u_{4, \text { beam }}=\sum_{i=1}^{n} \int_{A_{i}}\left(\frac{I_{12}}{I_{12}^{2}-I_{1} I_{2}} x+\frac{I_{2}}{I_{1} I_{2}-I_{12}^{2}} y\right)\left[N_{\text {shell }}\right] \\
\cdot\left\{u_{3, \text { shell }}\right\} d A+\sum_{i=1}^{n} \int_{l_{i}} \frac{t^{3}}{12}\left(\frac{I_{2}}{I_{1} I_{2}-I_{12}^{2}}\right)\left(\frac{d x}{d s}\right) \\
\cdot\left[N_{\text {shell }}\right]\left\{u_{4, \text { shell }}\right\} d l+\sum_{i=1}^{n} \int_{l_{i}} \frac{t^{3}}{12}\left(\frac{I_{12}}{I_{12}^{2}-I_{1} I_{2}}\right)\left(\frac{d x}{d s}\right) \\
\cdot\left[N_{\text {shell }}\right]\left\{u_{5, \text { shell }}\right\} d l .
\end{gathered}
$$

By the same way, the multipoint constraint equation for $u_{5, \text { beam }}$ can be expressed as

$$
\begin{gathered}
u_{5, \text { beam }}=\sum_{i=1}^{n} \int_{A_{i}}\left(\frac{I_{1}}{I_{12}^{2}-I_{1} I_{2}} x+\frac{I_{12}}{I_{1} I_{2}-I_{12}^{2}} y\right)\left[N_{\text {shell }}\right] \\
\cdot\left\{u_{3, \text { shell }}\right\} d A+\sum_{i=1}^{n} \int_{l_{i}} \frac{t^{3}}{12}\left(\frac{I_{12}}{I_{1} I_{2}-I_{12}^{2}}\right)\left(\frac{d x}{d s}\right) \\
\cdot\left[N_{\text {shell }}\right]\left\{u_{4, \text { shell }}\right\} d l+\sum_{i=1}^{n} \int_{l_{i}} \frac{t^{3}}{12}\left(\frac{I_{1}}{I_{12}^{2}-I_{1} I_{2}}\right)\left(\frac{d x}{d s}\right) \\
\cdot\left[N_{\text {shell }}\right]\left\{u_{5, \text { shell }}\right\} d l .
\end{gathered}
$$

2.3. $2 D$ and $3 D$ Elements Coupling. Figure 4 shows the coupling interface of 2D shell elements and 3D solid elements. In this figure, $u_{i}^{\prime}$ and $u_{i, \text { shell }}$ are the nodal displacement components of solid elements and shell elements, respectively, on the interface along axis $i$. According to the energy conservation principle, the work done of the force of shell elements should 
be equal to the work done of the nodal stresses of solid elements. Thus, the relationship of force of shell elements and nodal stresses of solid elements is given by

$$
\int_{L} F_{i}^{\prime} u_{i, \text { shell }} d x= \begin{cases}\int_{A} \sigma_{3 i} u_{i}^{\prime} d A, & (i=1,2,3) \\ \int_{A} \sigma_{33} u_{3}^{\prime} d A, & (i=4,5) \\ \int_{A} \sigma_{31} u_{1}^{\prime} d A, & (i=6),\end{cases}
$$

where $F_{i}^{\prime}$ is force component of shell elements in unit length along axis $i ; \sigma_{3 i}$ is nodal stress component of solid elements along axis $i$; $A$ is coupling interface area and $L$ is the coupling interface length (see Figure 4 ); $u_{i \text {,shell }}$ and $u_{i}^{\prime}$ are the displacement component of shell element and solid element on interface along axis $i$, respectively.

The force component $F_{i}^{\prime}$ can be formulated by the nodal stress on interface as

$$
F_{i}^{\prime}= \begin{cases}\int_{-t / 2}^{t / 2} \sigma_{3 i} d y, & (i=1,2,3) \\ \int_{-t / 2}^{t / 2} \sigma_{33} y d y, & (i=4) \\ \int_{-L / 2}^{L / 2} \sigma_{33} x d x, & (i=5) \\ \int_{-t / 2}^{t / 2} \sigma_{31} y d y, & (i=6),\end{cases}
$$

where $t$ is the thickness of shell element.
On the coupling interface, the nodal stresses of shell elements can be expressed as one-degree linear term and parabolic-quadratic term, respectively, as follows:

$$
\begin{aligned}
& \sigma_{31}=a+b y, \\
& \sigma_{32}=f\left(1-\frac{4 y^{2}}{t^{2}}\right), \\
& \sigma_{33}=c+d y+e x,
\end{aligned}
$$

where $a, b, c, d, e$, and $f$ are parameters.

The nodal stress $\sigma_{3 i}$ of shell element can be obtained by substituting (15), (13), and (14) into (11) as

$$
\begin{aligned}
& \sigma_{31}=\frac{F_{1}}{t}+\frac{12 F_{6}}{t^{3}} y, \\
& \sigma_{32}=\frac{3 F_{2}}{2 t}\left(1-\frac{4 y^{2}}{t^{2}}\right), \\
& \sigma_{33}=\frac{F_{3}}{t}+\frac{12 F_{4}}{t^{3}} y+\frac{12 F_{5}}{L^{3}} x .
\end{aligned}
$$

By substituting (15), (16), and (17) with $F_{1 \sim 6}=$ $\left[N_{\text {shell }}\right]\left\{F_{1 \sim 6}\right\}=\left\{F_{1 \sim 6}\right\}^{T}\left[N_{\text {shell }}\right]^{T}, u_{1 \sim 6}=\left[N_{\text {shell }}\right]\left\{u_{1 \sim 6}\right\}$, and $u_{1 \sim 3}^{\prime}=\left[N_{\text {solid }}\right]\left\{u_{1 \sim 3}^{\prime}\right\}$ into (10), the multipoint constraint equations for shell elements and solid elements can be written as

$$
\left\{u_{i}\right\}= \begin{cases}\frac{\int_{A}\left[N_{\text {shell }}\right]^{T}\left[N_{\text {solid }}\right] d A}{t \int_{L}\left[N_{\text {shell }}\right]^{T}\left[N_{\text {shell }}\right] d x}\left\{u_{1}^{\prime}\right\}=\left[X_{1}\right]\left[u_{1}^{\prime}\right], & (i=1) \\ \frac{3 \int_{A}\left(1-4 y^{2} / t^{2}\right)\left[N_{\text {shell }}\right]^{T}\left[N_{\text {solid }}\right] d A}{2 t \int_{L}\left[N_{\text {shell }}\right]^{T}\left[N_{\text {shell }}\right] d x}\left\{u_{2}^{\prime}\right\}=\left[X_{2}\right]\left[u_{2}^{\prime}\right], & (i=2) \\ \frac{\int_{A}\left[N_{\text {shell }}\right]^{T}\left[N_{\text {solid }}\right] d A}{t \int_{L}\left[N_{\text {shell }}\right]^{T}\left[N_{\text {shell }}\right] d x}\left\{u_{2}^{\prime}\right\}=\left[X_{3}\right]\left[u_{2}^{\prime}\right], & (i=3) \\ \frac{12 \int_{A} y\left[N_{\text {shell }}\right]^{T}\left[N_{\text {solid }}\right] d A}{t^{3} \int_{L}\left[N_{\text {shell }}\right]^{T}\left[N_{\text {shell }}\right] d x}\left\{u_{3}^{\prime}\right\}=\left[X_{4}\right]\left[u_{3}^{\prime}\right], & (i=4) \\ \frac{12 \int_{A} x\left[N_{\text {shell }}\right]^{T}\left[N_{\text {solid }}\right] d A}{L^{3} \int_{t}\left[N_{\text {shell }}\right]^{T}\left[N_{\text {shell }}\right] d y}\left\{u_{3}^{\prime}\right\}=\left[X_{5}\right]\left[u_{3}^{\prime}\right], & (i=5) \\ \frac{12 \int_{A} y\left[N_{\text {shell }}\right]^{T}\left[N_{\text {solid }}\right] d A}{t^{3} \int_{L}\left[N_{\text {shell }}\right]^{T}\left[N_{\text {shell }}\right] d x}\left\{u_{1}^{\prime}\right\}=\left[X_{6}\right]\left[u_{1}^{\prime}\right], & (i=6),\end{cases}
$$

where $\left\{u_{1 \sim 6}\right\}$ and $\left\{u_{1 \sim 3}^{\prime}\right\}$ are nodal displacement matrixes for shell elements and solid elements, respectively; $\left[N_{\text {shell }}\right]$ and $\left[N_{\text {solid }}\right]$ are shape functions for shell elements and solid elements, respectively; $\left\{F_{1 \sim 6}\right\}$ is nodal force matrix for shell elements; $\left[u_{1 \sim 3}^{\prime}\right]$ is nodal displacement matrix for solid elements on the coupling interface. 


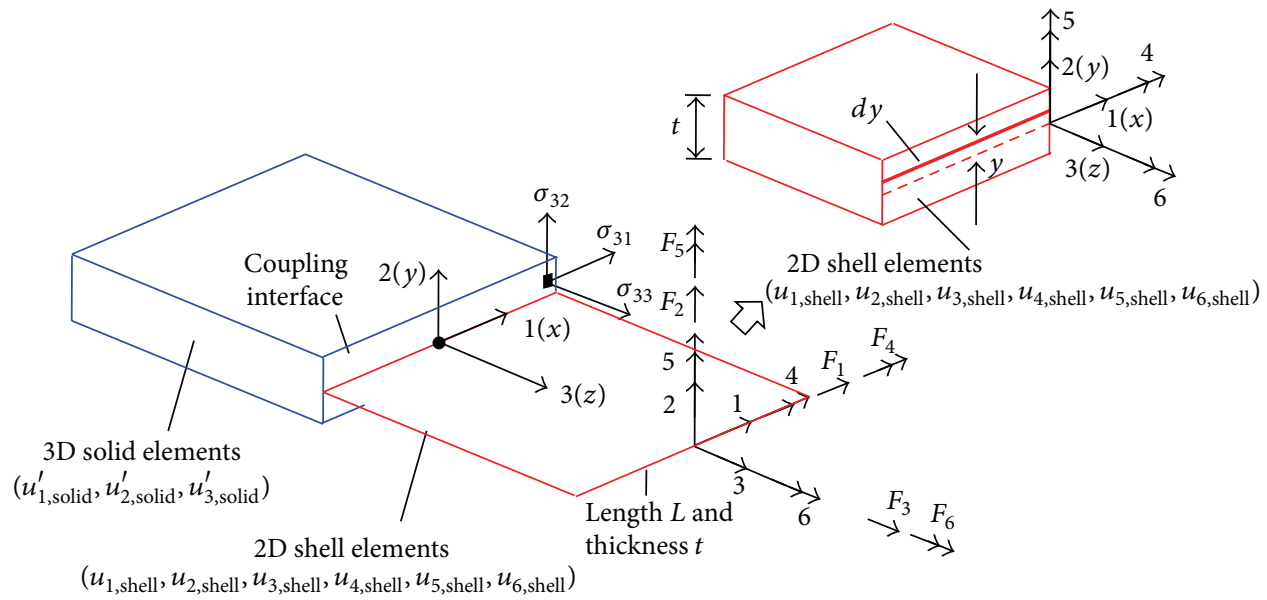

FIGURE 4: Coupling of 2D elements with 3D elements.

TABLE 1: Suggested values of $\alpha_{i}$ for each level.

\begin{tabular}{|c|c|c|c|}
\hline Structural & & Material level & \\
\hline & Concrete in compression & Concrete in tension & Steel $\mathrm{r}$ \\
\hline$\alpha_{i}$ & 0.189 & 0.205 & \\
\hline
\end{tabular}

The generalized damage model and multilevel performance are shown in Figure 5. In this figure, $\delta$ is the generalized deformation for every level, while $\delta_{i}, \delta_{i, e}$, and $\delta_{i, u}$ represent the deformation, elastic limit deformation, and ultimate deformation for level $i$, respectively; $F$ is the generalized force which corresponds to the generalized deformation $\delta$; $F_{i}^{\prime}$ and $F_{i}$ represent the force for undamaged and damaged configuration, respectively, while $F_{i, u}^{\prime}$ and $F_{i, u}$ are the ultimate bearing capacity for undamaged and damaged configuration, respectively; $K$ is the generalized stiffness which is the ratio of the generalized force $F$ to the generalized deformation $\delta$ and $K_{i, 0}, K_{i}$, and $K_{i \text {,eq }}$ are the initial stiffness, secant stiffness, and equivalent stiffness, respectively. The equivalent stiffness $K_{i, \text { eq }}$ represents the effect of the damage on the stiffness of the undamaged configuration and can be expressed as $K_{i \text {,eq }}=$ $\left(\delta_{i} \cdot K_{i}-\delta_{i, e} \cdot K_{i, 0}\right) /\left(\delta_{i}-\delta_{i, e}\right)$. As shown in Figure 5 , the loss of bearing capacity of the damage configuration is used to define the generalized multilevel damage model as

$$
\begin{gathered}
D_{i}=\left(\delta_{i, d} \cdot d_{i}\right)^{\alpha_{i}}, \\
d_{i}=1-\frac{K_{i, \mathrm{eq}}}{K_{i, 0}}, \\
\delta_{i, d}=\frac{\delta_{i}-\delta_{i, e}}{\delta_{i, u}-\delta_{i, e}}
\end{gathered}
$$

where $D_{i}$ is the generalized multilevel damage model; $d_{i}$ is the generalized stiffness damage; $\delta_{i, d}$ is the generalized deformation damage; $\alpha_{i}$ is the corresponding parameter, which are obtained by plenty statistical analysis based on (19) and (21), as shown in Table 1 .

Figure 5 also shows the generalized performance with five levels as follows: slight damage level (SD or I), minor damage level (MD or II), moderate damage level (SE or III), severe damage level (SE or IV), and collapse damage level (CO or V). The limit damage values of I, II, III, IV, and V are $0.2,0.4,0.6,0.8$, and 1.0 , respectively, for every structural level (e.g., material, member, and structure level). For each structural level, the deformation variables are taken as the damage indicators as shown in Figure 5.

At structure level, $\Delta_{e}, \Delta_{y}, \Delta_{\mathrm{sp}}, \Delta_{c}, \Delta_{\mathrm{bu}}, \Delta_{u}$ are the structure top displacement and correspond to elastic limit, onset of first yield, concrete spalling in weaker elements, onset of concrete crushing, onset of disclosing of buckled reinforcement, and structure collapse, respectively.

At storey level, $\theta_{e}, \theta_{y}, \theta_{\mathrm{sp}}, \theta_{c}, \theta_{\mathrm{bu}}, \theta_{u}$ are the interstorey drift ratio and correspond to elastic behavior limit, onset of first yield, concrete spalling in weaker elements, onset of concrete crushing, onset of disclosing of buckled reinforcement, and storey failure, respectively.

At member level, $u_{e}, u_{y}, u_{\mathrm{sp}}, u_{c}, u_{\mathrm{bu}}, u_{u}$ are the element (beam or column) drift and correspond to elastic behavior limit, first yield of steel reinforcement, spalling of exterior concrete, crushing of core concrete, buckling of steel reinforcement, and element failure, respectively.

At section level, $\phi_{e}, \phi_{y}, \phi_{\text {sp }}, \phi_{c}, \phi_{\mathrm{bu}}, \phi_{u}$ are the section curvature and correspond to elastic behavior limit, first yield of steel reinforcement, spalling of exterior concrete, crushing of core concrete, buckling of steel reinforcement, and element failure, respectively.

At material level, the values of the corresponding stresses of strain damage indicators for concrete and reinforcement 


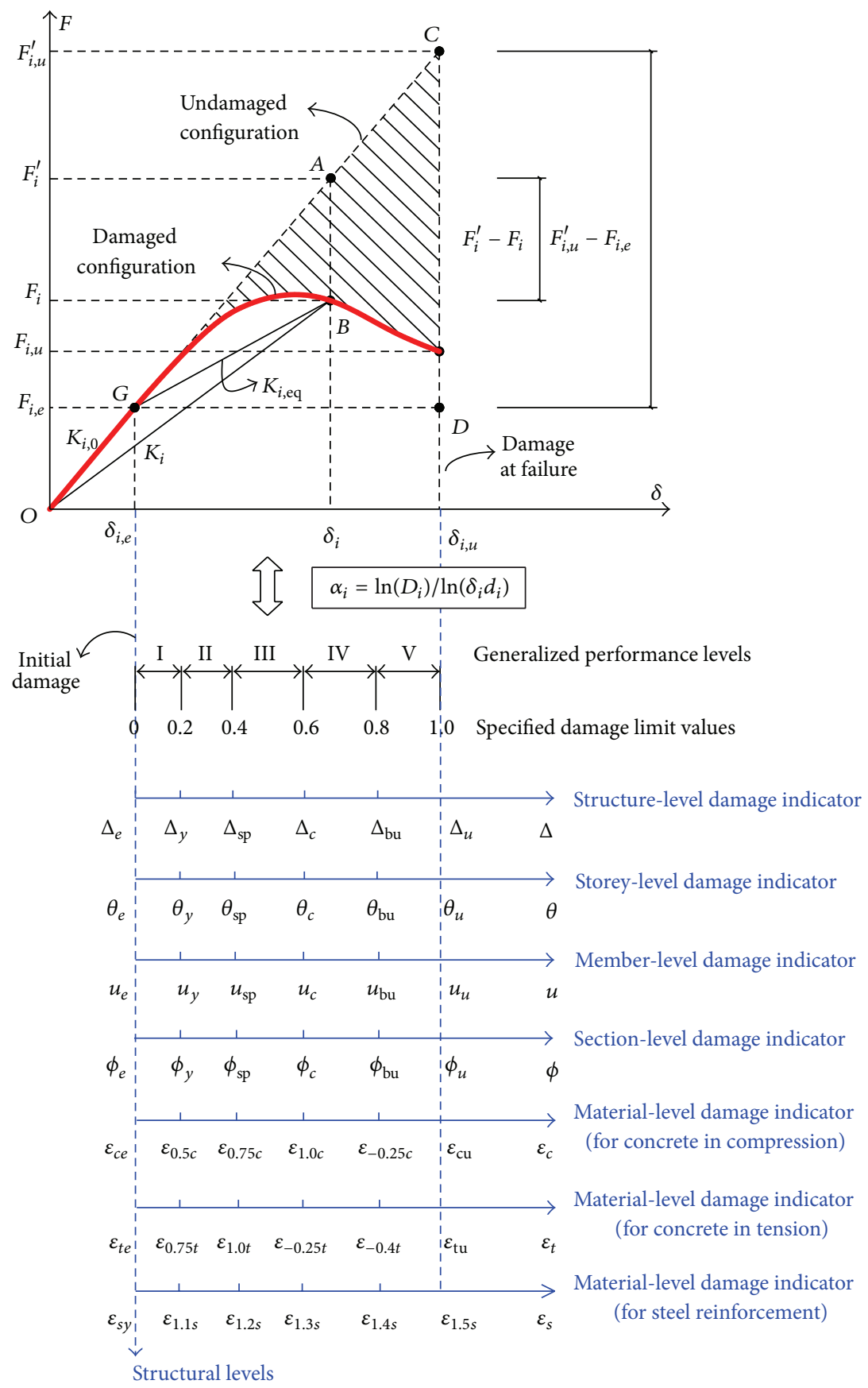

FIGURE 5: Generalized damage model combined with multiperformance levels.

are listed in Table 2. As shown in Figure 5, $\varepsilon_{\mathrm{cu}}, \varepsilon_{\mathrm{tu}}$ are the concrete ultimate compressive, tensile strain; $\varepsilon_{1.5 s}$ denotes the steel reinforcement strain corresponding to stress of $1.5 f_{y}$, in which $f_{y}$ is the reinforcement yield strength. In Table 2, $\varepsilon_{c}$, $\varepsilon_{t}$ denote the concrete compressive, tensile strain damage indicator, respectively; $\sigma_{c}, \sigma_{t}$ denote the concrete compressive, tensile stress corresponding to $\varepsilon_{c}$, $\varepsilon_{t}$, respectively; $\varepsilon_{s}$ is the reinforcement strain damage indicator corresponding to stress $\sigma_{s}$.
TABLE 2: The values of corresponding stresses of strain damage indicators at material level.

\begin{tabular}{cccccc}
\hline$\varepsilon_{c}$ & $\varepsilon_{c e}$ & $\varepsilon_{0.5 c}$ & $\varepsilon_{0.75 c}$ & $\varepsilon_{1.0 c}$ & $\varepsilon_{-0.25 c}$ \\
$\sigma_{c}$ & $0.3 f_{c}^{\prime}$ & $0.5 f_{c}^{\prime}$ & $0.75 f_{c}^{\prime}$ & $f_{c}^{\prime}$ & $0.75 f_{c}^{\prime}$ \\
\hline$\varepsilon_{t}$ & $\varepsilon_{t e}$ & $\varepsilon_{0.75 t}$ & $\varepsilon_{1.0 t}$ & $\varepsilon_{-0.25 t}$ & $\varepsilon_{-0.4 t}$ \\
$\sigma_{t}$ & $0.6 f_{t}$ & $0.75 f_{t}$ & $f_{t}$ & $0.75 f_{t}$ & $0.6 f_{t}$ \\
\hline$\varepsilon_{s}$ & $\varepsilon_{s y}$ & $\varepsilon_{1.1 s}$ & $\varepsilon_{1.2 s}$ & $\varepsilon_{1.3 s}$ & $\varepsilon_{1.4 s}$ \\
$\sigma_{s}$ & $f_{y}$ & $1.1 f_{y}$ & $1.2 f_{y}$ & $1.3 f_{y}$ & $1.4 f_{y}$ \\
\hline
\end{tabular}




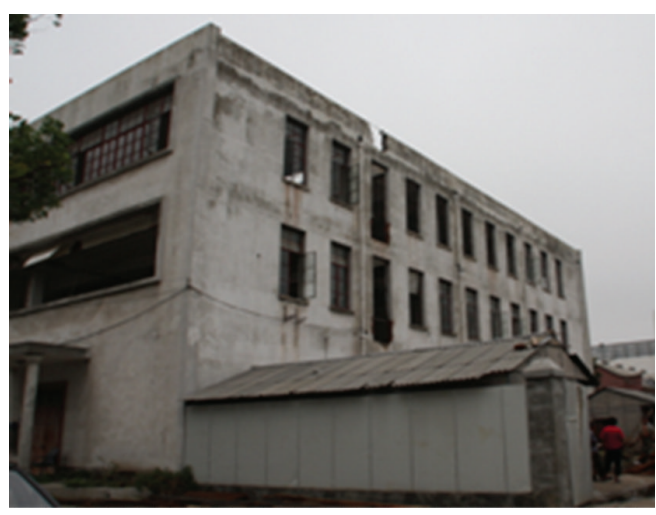

Test structure

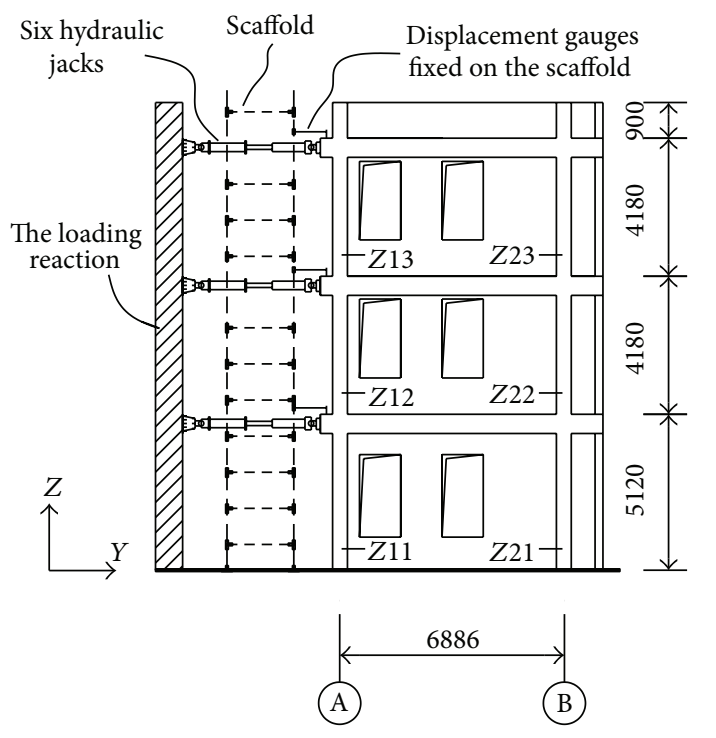

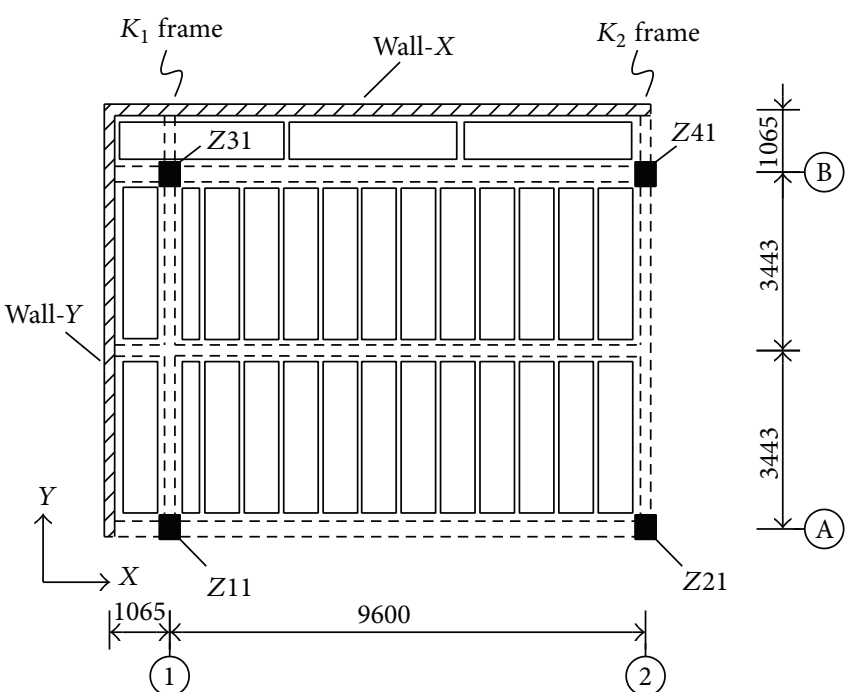

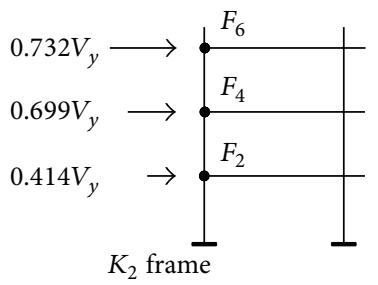

FIGURE 6: The test structure and loading method (unit: $\times 10^{-3} \mathrm{~m}$ ).

It is clear that the generalized multilevel damage model (Equation (19)) covers all the performance and structural levels using different damage indicators. Thus, the proposed generalized damage model combined with multilevel performance can be used here to study damage evolution at various structural levels.

\section{Multiscale Analysis for a Real RC Structure}

4.1. Test and Micro-Macro-Coupling FEM. The test structure and loading system are shown in Figure 6. The original RC frame structure was built at the beginning of the 1980s in Shanghai, China, with three floors, five-by-five bays, exterior walls, and grillage foundation. The test structure was separated from the original building with one-by-one bay and the remainder structure was used as the loading reaction. Figure 6 gives the geometry of the test structure. The floor structure was made of precast concrete slabs of $120 \times 830 \mathrm{~mm}^{2}$ and $120 \times 430 \mathrm{~mm}^{2}$ cross sections.
The Young modulus of concrete is measured as $2.68 \times$ $10^{4} \mathrm{~N} / \mathrm{mm}^{2}$. The test strength of concrete is measured as $22.69 \mathrm{~N} / \mathrm{mm}^{2}$. The yielding strength and limit strength of the longitudinal reinforcement are measured as $325.93 \mathrm{~N} / \mathrm{mm}^{2}$ and $482.79 \mathrm{~N} / \mathrm{mm}^{2}$, respectively. The yielding strength and limit strength of the stirrups reinforcement are measured as 251.27 N/mm $\mathrm{m}^{2}$ and $349.91 \mathrm{~N} / \mathrm{mm}^{2}$, respectively.

The earthquake action is assumed to be lateral forces that acted on each storey as an inverted triangle distribution. In the test, the lateral loading was applied on six beam-column joints by six hydraulic jacks as shown in Figure 6. A scaffold was fixed on the ground and six displacement gauges were installed on it to measure the absolute displacements of the six joints separately during the test. The vector of lateral loading $\left\{F_{1}, F_{2}, F_{3}, F_{4}, F_{5}, F_{6}\right\}$, as shown in Figure 6, was achieved as $\{0.535,0.414,0.898,0.699,1.000,0.732\} V_{y}$ according to the distribution of the concentrated mass of each joint. $V_{y}$ is the lateral force of $F_{5}$, which was taken as the referential loading. At the beginning, the loading was force-controlled 


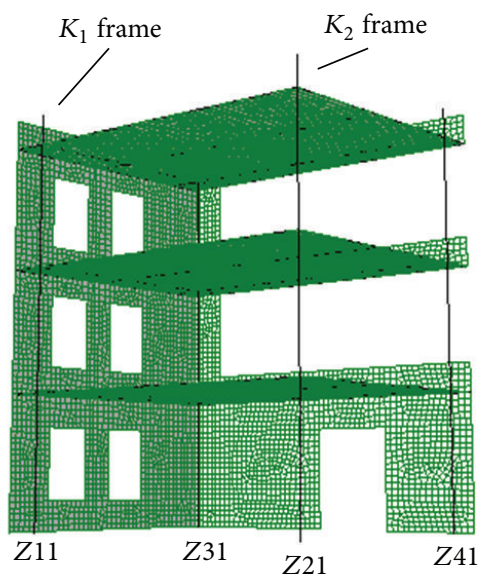

(a)

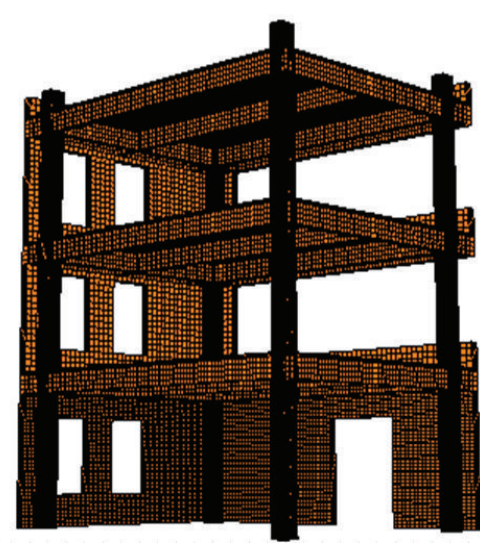

(b)

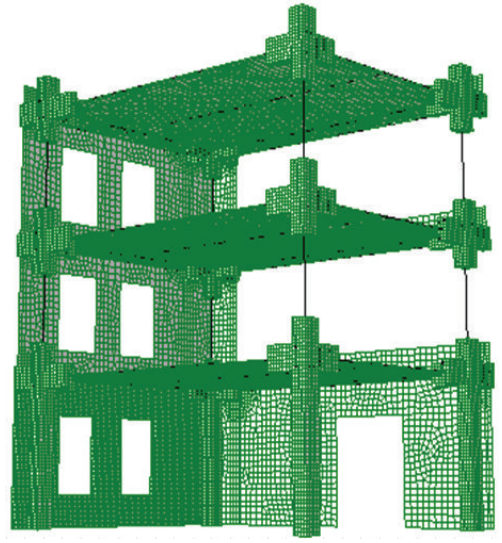

(c)

FIGURE 7: Numerical computational model: (a) macro-scale FEM; (b) micro-scale FEM; (c) element-coupling model.

mode with force increment $15 \mathrm{kN}$ of $F_{6}$. At last, the loading was displacement-controlled mode with the displacement increment $20 \mathrm{~mm}$ of $F_{5}$.

Three numerical models are used to simulate test as shown in Figure 7. In those finite element models, the concrete behavior was described by concrete plastic-damage model [28]. The masonry walls were also described by concrete plastic-damage model by equating the ratio of the biaxial compressive strength to the uniaxial compressive strength to 2.0. Although each numerical model could reflect the global structure response, not all models could capture the damage details at micro-scale. In the macro-scale finite element model (see Figure 7(a)), the beams and columns were modeled by B31 element, which is a Timoshenko 2node linear beam element in space. The walls and floors were modeled by S3 element, which is a three-node triangular general-purpose shell element. There are total 12885 nodes in this model, so it has a low computational cost. However, obviously, this model could not capture the damage details at micro-scale.

In order to capture the damage details at micro-scale, the micro-scale finite element model (see Figure 7(b)) was established using ANSYS package $[29,30]$. The columns and beams were modeled by 3D element SOLID65. The floors were assumed to be in elasticity and modeled by SHELL143 element. Longitudinal rebars and transverse stirrups were modeled by $1 \mathrm{D}$ truss element LINK8. Because the shell element could not simulate the fracture behavior under tension action, an equivalent concrete model was used for brick masonry with 3D element SOLID65. The total number of nodes in this model is 102331, which indicate that it has higher computational cost than macro-scale finite element model. Aiming to obtain the damage details at micro-scale with good computational cost, a mixed-micro-macro-scale finite element model, that is, the element-coupling model shown in Figure 7(c), was proposed with the aid of (1) to (18). It includes the advantages of the macro-scale and micro-scale finite element model. In major damage regions, the concrete and masonry were modeled by C3D8R elements, which is the 8node linear brick, reduced integration with hourglass control

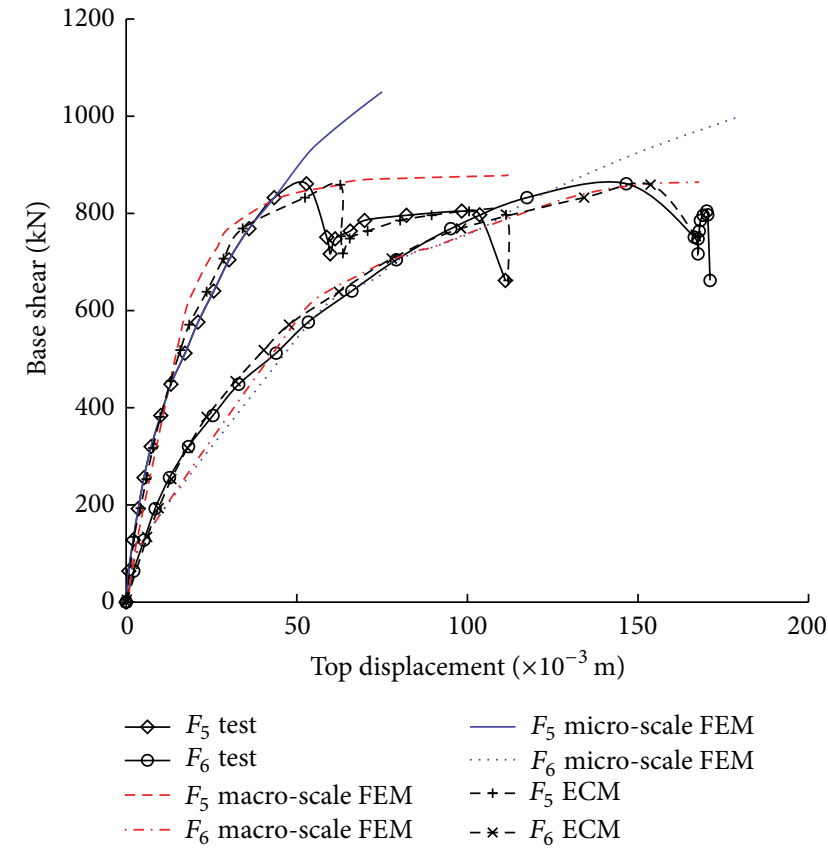

FIGURE 8: The primarily calculated bearing capacity results compared with the test results.

continuum element. The steel reinforcement was modeled by the T3D2 elements, which is the 3D stress/displacement 2node linear displacement truss element. Steel reinforcement elements were embedded in the concrete elements. In minor damage regions, the beams and columns were modeled by B31 elements, and the floors and walls were modeled by S3 elements. The plastic-damage model was used for concrete material. Using the same mesh refinements of micro-scale FEM, the total number of nodes in the model is 80544 , which indicate that its computational cost is between the macroscale and micro-scale FEM.

Figure 8 shows the comparisons between test and numerical results of total base shear versus top drift angle of $K_{1}$ and $K_{2}$ single frame. At the beginning, no visible cracks were 

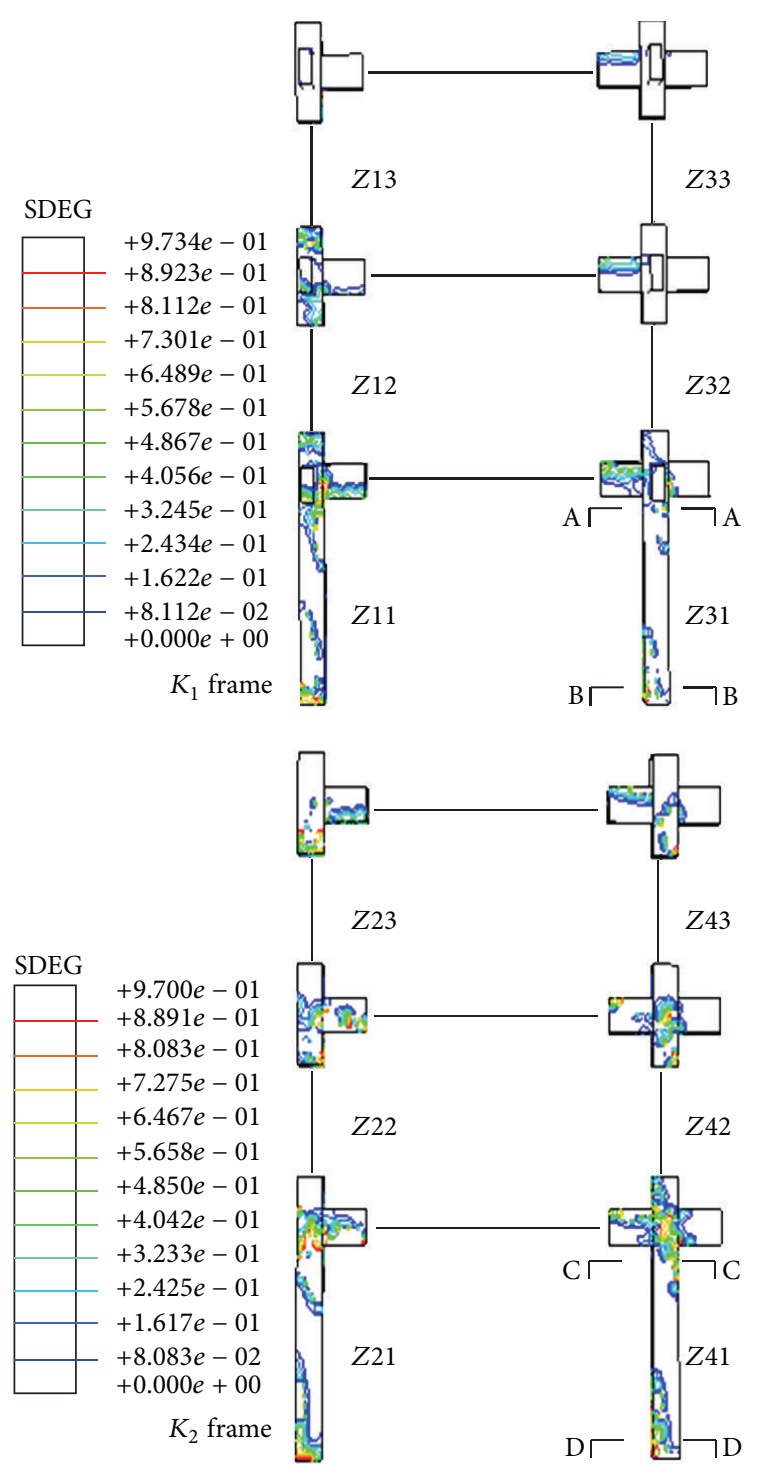

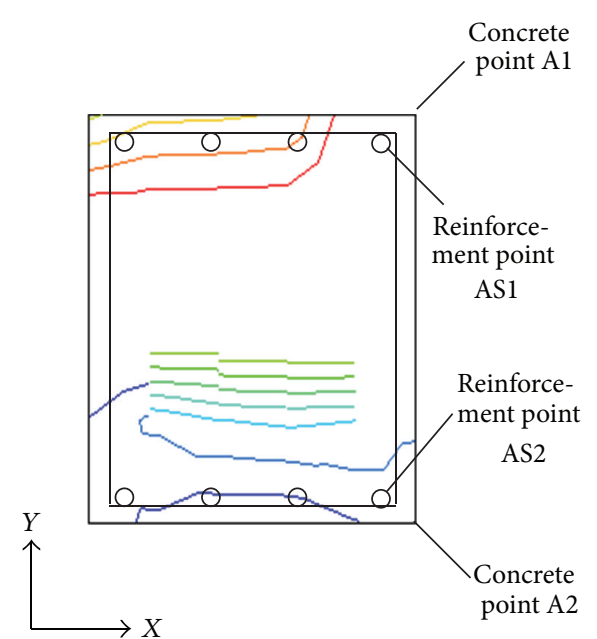

Section A

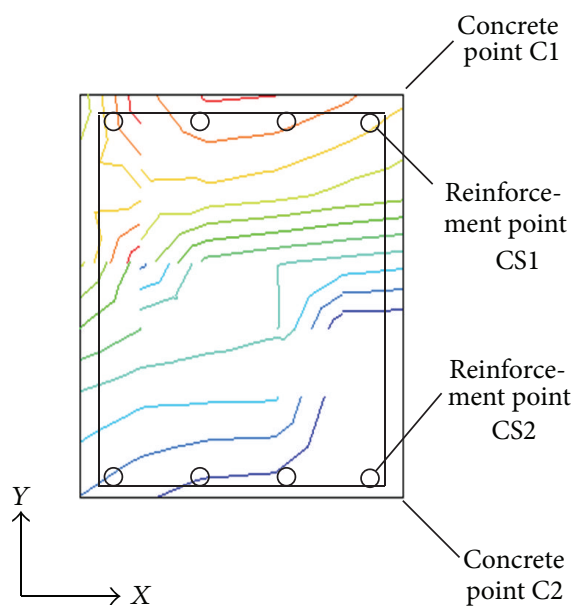

Section C

FIgURE 9: The calculation failure damage states of $K_{1} / K_{2}$ frames and test damage results.

observed on the structural members. Until the displacements of $F_{5}$ and $F_{6}$ reached $17.3 \mathrm{~mm}$ and $43.9 \mathrm{~mm}$, respectively, some minor cracks appeared mainly at the ends of bottom columns. After that, the structure had plastic deformation. Thus, this state was taken as the elastic limit state. When the displacement of $F_{5}$ and $F_{6}$ reached $52.9 \mathrm{~mm}$ and $146.6 \mathrm{~mm}$, the structure got the peak base shear of $859 \mathrm{kN}$. At this state, some inclined cracks occurred at the ends of the bottom columns. While the displacement of $F_{6}$ and $F_{6}$ reached $166.5 \mathrm{~mm}$, the cracks on top of column $Z 41$ expanded and fractured suddenly. Finally, column $Z 31$ also fractured at top end when the displacement of $F_{5}$ reached $111.1 \mathrm{~mm}$. It is the collapse level state. The displacement differences of $F_{5}$ and $F_{6}$ at failure state indicates that torsional deformation effected heavily the structure behavior due to the asymmetry walls. The failure damages are shown in Figure 9. It can be seen that the element-coupling model could capture the damage details in micro-scale with a relatively good computational cost.
4.2. Multiscale Damage Assessment. Using (19), the generalized damage at different structural level could be obtained. Figure 10 shows the calculated generalized damage evolution at different levels. The results of damage indicators, that is, structural drift, interstorey drift ratio, member drift, curvature and strain or stress, and generalized damage at different levels of states S1, S2, and S3, are listed separately in Table 3. In this table, $\Delta_{F 5}$ means the drift of loading point $F_{5}$ (see Figure 6) and $D$ means the damage of the structure; $\theta_{\text {storey-1 }}$ means the interstorey drift ration of storey1 and $D_{\text {storey- }}$ means the damage of storey- $1 ; u_{Z 31}$ means the drift of column $Z 31$ (see Figure 7); $D_{Z 31}$ means the damage of column $Z 31 ; \phi_{\mathrm{A}}$ means the curvature of section A (see Figure 9), and $D_{\mathrm{A}}$ means the damage of section $\mathrm{A} ; \varepsilon_{\mathrm{A} 1}$ means the strain of concrete point $\mathrm{Al}$, and $D_{\mathrm{A} 1}$ means the damage of concrete point A1; $\sigma_{\mathrm{AS} 2}$ means the stress of reinforcement point AS2 (see Figure 9), and $D_{\text {AS2 }}$ means the damage of reinforcement point AS2. 
TABLE 3: The values of damage indicators and generalized damage at different level.

\begin{tabular}{lcccccccccccc}
\hline \multirow{2}{*}{ Damage state } & \multicolumn{2}{c}{ Structure level } & \multicolumn{2}{c}{ Storey level } & \multicolumn{2}{c}{ Member level } & \multicolumn{3}{c}{ Section level } & \multicolumn{3}{c}{ Material level } \\
& $\Delta_{F 5}\left(\times 10^{-3} \mathrm{~m}\right)$ & $D$ & $\theta_{\text {storey-1 }}$ & $D_{\text {storey-1 }}$ & $u_{Z 31}\left(\times 10^{-3} \mathrm{~m}\right)$ & $D_{Z 31}$ & $\phi_{\mathrm{A}}\left(\times 10^{-6}\right)$ & $D_{\mathrm{A}}$ & $\varepsilon_{\mathrm{A} 1}\left(\times 10^{-3}\right)$ & $D_{\mathrm{A} 1}$ & $\sigma_{\mathrm{AS} 2}(\mathrm{MPa})$ & $D_{\mathrm{AS} 2}$ \\
\hline S1 & 19.6 & 0.56 & 0.001 & 0.69 & 10.7 & 0 & 0.9 & 0 & 0.29 & 0.12 & 114.7 & 0 \\
S2 & 59.5 & 0.80 & 0.005 & 0.88 & 50.5 & 0.54 & 2.6 & 0 & 0.48 & 0.31 & 329.4 & 0.02 \\
S3 & 113.7 & 0.84 & 0.016 & 0.88 & 88.7 & 0.69 & 5.9 & 0.3 & 0.83 & 0.44 & 337.9 & 0.08 \\
\hline
\end{tabular}

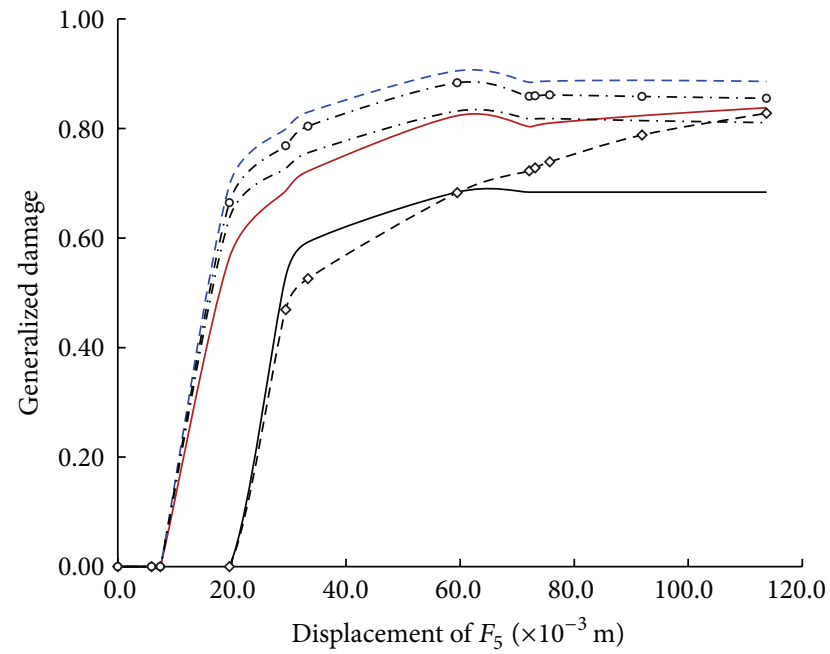

Structure level and storey level

$$
\begin{array}{ll}
- \text { Structure } & - \text { Storey-3 } \\
--- \text { Storey-1 } & -\diamond-K_{1} \text { frame } \\
--- \text { Storey-2 } & -\infty-K_{2} \text { frame }
\end{array}
$$

(a) Damage evolutions at structure level and storey level

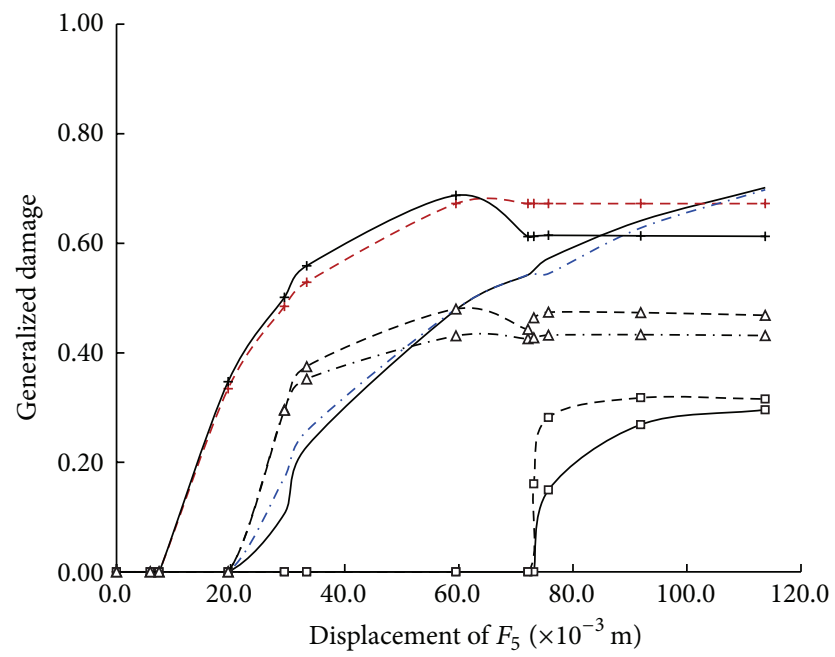

Member level and section level

$\begin{array}{ll}- \text { Column Z11 } & -- \text { Section A } \\ -+- \text { Column Z21 } & -\square-\text { Section B } \\ --\cdot \text { Column Z31 } & -\Delta-\text { Scetion C } \\ - \text { - Column Z41 } & -\Delta-\text { Section D }\end{array}$

(b) Damage evolutions at member level and section level

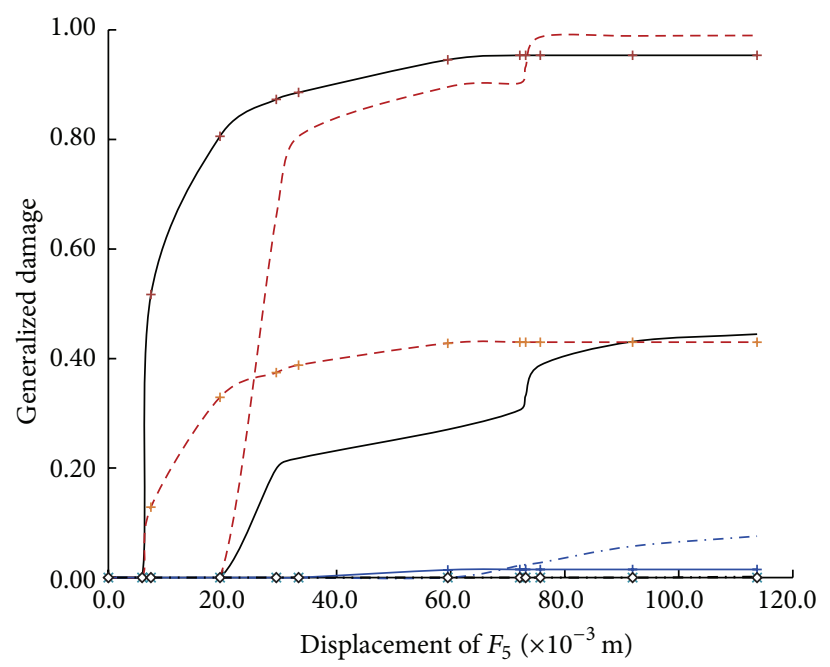

Material level

$\begin{array}{ll}- \text { A1 } & --\mathrm{C} 1 \\ --- \text { A2 } & -+- \text { C2 } \\ -\cdot-\text { AS1 } & + \text { CS1 } \\ --\cdots \text { AS2 } & \rightarrow-. \text { CS2 }\end{array}$

(c) Damage evolutions at material level

FIgURE 10: The calculated multilevel damage evolutions. 
At damage state S1, Figure 9 shows that the damage performances of $K_{2}$ frame, storey-1, storey-2, and structure reached to moderate damage level, while $K_{1}$ frame and storey-3 almost had no damage. The damage value of global structure and storey- 1 is 0.56 and 0.69 , respectively, as shown in Table 3. The damage performances of column $Z 21$ and $Z 41$ reached minor damage level, while sections $C$ and $D$ almost had no damage. At material level, the damage performances of concrete points $\mathrm{C} 1$ (in tension) and $\mathrm{C} 2$ (in compression) reached ultimate damage level and minor damage level, respectively, while the damage of reinforcement points CS1 and CS2 was very minor.

At state S2, Figure 9 shows that the damage performances of $K_{2}$ frame, storey-1, storey-2, and structure reached ultimate damage level, while $K_{1}$ frame and storey- 3 reached moderate damage level. The damage value of structure and storey- 2 is 0.80 and 0.88 , respectively, as shown in Table 3 . The damage performances of columns $Z 21$ and $Z 41$ reached moderate damage level. At material level, the damage performances of concrete points $\mathrm{C} 1$ (in tension) and C2 (in compression) reached ultimate damage level and moderate damage level, respectively, while the damage of reinforcement points CS1 and CS2 was very minor.

At state S3, Figure 9 shows that the damage performance of $K_{1}$ frame reached ultimate damage level. The damage performances of columns $Z 11$ and column $Z 31$ reached moderate damage level. The damage value of column $Z 31$ is 0.69 as shown in Table 3. At material level, the damage performances of concrete points A1 (in tension) and A2 (in compression) reached ultimate damage level and moderate damage level, respectively, while the damage of reinforcement points AS1 and AS2 was very small.

It can be seen that the multilevel damage evolution analysis gives a complete explanation of damage mechanism from material level to structure level for this RC structure. This method also helps to find the damage process and damage state for every level (i.e., structure, storey, member, section, or material). Therefore, this method could provide more damage performance details (not only at macro-scale but also at micro-scale) for the performance-based design.

\section{Conclusions}

Based on the energy conservation principle, the coupling of mixed dimensional elements could be established in finite element model. This mixed-micro-macro-scale finite element model could capture the damage details at micro-scale and global structural nonlinear behavior together. When using the same mesh refinements of macro-scale finite element models, it qualitatively has a relative good computational cost. It is available for the damage numerical analysis for RC structures even for some high-rise or complex RC structures.

Aiming to assess the damage evolution from microscale to macro-scale, a generalized damage model combined with multilevel performance is proposed. By using elementcoupling model, it has been used to evaluate the damage of a real RC frame structure subjected by lateral loading in situ. The very good agreement between the calculation and test results shows that the proposed generalized damage model can correctly evaluate the damage states or evolutions for different structural and performance levels. It is a very useful tool for analyzing damage mechanisms from material level to structure level of RC structures.

\section{Conflict of Interests}

The author declares that there is no conflict of interests regarding the publication of this paper.

\section{Acknowledgments}

The first author acknowledges the support of the National Natural Science Foundation of China under Grant no. 51308286 and the Jiangsu Province Natural Science Foundation under Grant no. BK20130944.

\section{References}

[1] S.-H. Jeong and A. S. Elnashai, "Analytical assessment of an irregular RC frame for full-scale 3D pseudo-dynamic testing part II: condition assessment and test deployment," Journal of Earthquake Engineering, vol. 9, no. 2, pp. 265-284, 2005.

[2] S. Hans, C. Boutin, E. Ibrahim, and P. Roussillon, "In situ experiments and seismic analysis of existing buildings. Part I: experimental investigations," Earthquake Engineering and Structural Dynamics, vol. 34, no. 12, pp. 1513-1529, 2005.

[3] E. Spacone, F. C. Filippou, and F. F. Taucer, "Fibre beam-column model for non-linear analysis of R/C frames: part I. Formulation," Earthquake Engineering and Structural Dynamics, vol. 25, no. 7, pp. 711-725, 1996.

[4] P. Mata, A. H. Barbat, and S. Oller, "Two-scale approach for the nonlinear dynamic analysis of RC structures with local nonprismatic parts," Engineering Structures, vol. 30, no. 12, pp. 36673680, 2008.

[5] R. W. McCune, C. G. Armstrong, and D. J. Robinson, "Mixeddimensional coupling in finite element models," International Journal for Numerical Methods in Engineering, vol. 49, no. 6, pp. 725-750, 2000.

[6] K. W. Shim, D. J. Monaghan, and C. G. Armstrong, "Mixed dimensional coupling in finite element stress analysis," Engineering with Computers, vol. 18, no. 3, pp. 241-252, 2002.

[7] E. Garusi and A. Tralli, "A hybrid stress-assumed transition element for solid-to-beam and plate-to-beam connections," Computers and Structures, vol. 80, no. 2, pp. 105-115, 2002.

[8] A. D. Hanganu, E. Oñate, and A. H. Barbat, "A finite element methodology for local/global damage evaluation in civil engineering structures," Computers \& Structures, vol. 80, no. 20-21, pp. 1667-1687, 2002.

[9] J.-G. Yue, A. Fafitis, J. Qian, and T. Lei, "Application of 1D/3D finite elements coupling for structural nonlinear analysis," Journal of Central South University of Technology, vol. 18, no. 3, pp. 889-897, 2011.

[10] H.-S. Kim and S.-M. Hong, "Formulation of transition elements for the analysis of coupled wall structures," Computers and Structures, vol. 57, no. 2, pp. 333-344, 1995.

[11] E. Cosenza and G. Manfredi, "Damage indices and damage measures," Earthquake Engineering and Structural Dynamics, vol. 2, no. 1, pp. 50-59, 2000. 
[12] G. H. Powell and R. Allahabadi, "Seismic damage prediction by deterministic methods: concepts and procedures," Earthquake Engineering \& Structural Dynamics, vol. 16, no. 5, pp. 719-734, 1988.

[13] W. B. Kraetzig, I. F. Meyer, and K. Meskouris, "Damage evolution in reinforced concrete members under cyclic loading," in Proceedings of the 5th International Conference on Structural Safety and Reliability, vol. 2, pp. 795-802, San Francisco, Calif, USA, August 1989.

[14] H. Banon and D. Veneziano, "Seismic safety of reinforced concrete members and structures," Earthquake Engineering \& Structural Dynamics, vol. 10, no. 2, pp. 179-193, 1982.

[15] J.-F. Wang, C.-C. Lin, G.-L. Lin, and C.-H. Yang, "Story damage identification of irregular buildings based on earthquake records," Earthquake Spectra, vol. 29, no. 3, pp. 963-985, 2013.

[16] Y.-J. Park and A. H.-S. Ang, "Mechanistic seismic damage model for reinforced concrete," Journal of Structural Engineering, vol. 111, no. 4, pp. 722-739, 1985.

[17] H. Sucuoglu and A. Erberik, "Energy-based hysteresis and damage models for deteriorating systems," Earthquake Engineering and Structural Dynamics, vol. 33, no. 1, pp. 69-88, 2004.

[18] G. S. Kamaris, G. D. Hatzigeorgiou, and D. E. Beskos, "A new damage index for plane steel frames exhibiting strength and stiffness degradation under seismic motion," Engineering Structures, vol. 46, pp. 727-736, 2013.

[19] S. Amziane and J. F. Dubé, "Global RC structural damage index based on the assessment of local material damage," Journal of Advanced Concrete Technology, vol. 6, no. 3, pp. 459-468, 2008.

[20] A. H. Barbat, S. Oller, E. Oñate, and A. Hanganu, "Viscous damage model for Timoshenko beam structures," International Journal of Solids and Structures, vol. 34, no. 30, pp. 3953-3976, 1997.

[21] R. Scotta, L. Tesser, R. Vitaliani, and A. Saetta, "Global damage indexes for the seismic performance assessement of RC structures," Earthquake Engineering \& Structural Dynamics, vol. 38, no. 8, pp. 1027-1049, 2009.

[22] Y. J. Park, A. H.-S. Ang, and Y. K. Wen, "Damage limiting: a seismic design of building," Earthquake Spectra, vol. 3, no. 1, pp. 1-26, 1987.

[23] M. J. N. Priestley, G. M. Calvi, and M. J. Kowalsky, DisplacementBased Seismic Design of Structures, IUSS PRESS, Pavia, Italy, 2007.

[24] FEMA, "NEHRP guidelines for the seismic rehabilitation of buidlings," FEMA 356, Federal Emergency Management Agency, Washington, DC, USA, 2000.

[25] BS, "Eurocode 8: design of structures for earthquake resistance-part 3: assessment and retrofitting of buildings," BS EN 1998-3, European Committee of Standardization, Brussels, Belgium, 2005.

[26] ASCE, "Seismic rehabilitation of existing buildings," ASCE/SEI 41, American Society of Civil Enginees, Reston, Va, USA, 2006.

[27] ABAQUS, ABAQUS Analysis User's Manual, Version 6.4, Hibbitt, Karlsson \& Sorensen, Pawtucket, RI, USA, 2003.

[28] J. Lubliner, J. Oliver, S. Oller, and E. Oñate, "A plastic-damage model for concrete," International Journal of Solids and Structures, vol. 25, no. 3, pp. 299-326, 1989.

[29] ANSYS, Simulation Technology, Structural Analysis, Version 9.0, Ansys Inc, Cecil Township, Pa, USA, 2005.

[30] J. Qian, G. Y. Zhao, T. Lei, and X. L. Lu, "Numerical analysis of an existing RC frame by using 3D elements," Journal of Earthquake and Tsunami, vol. 5, no. 1, pp. 47-55, 2011. 

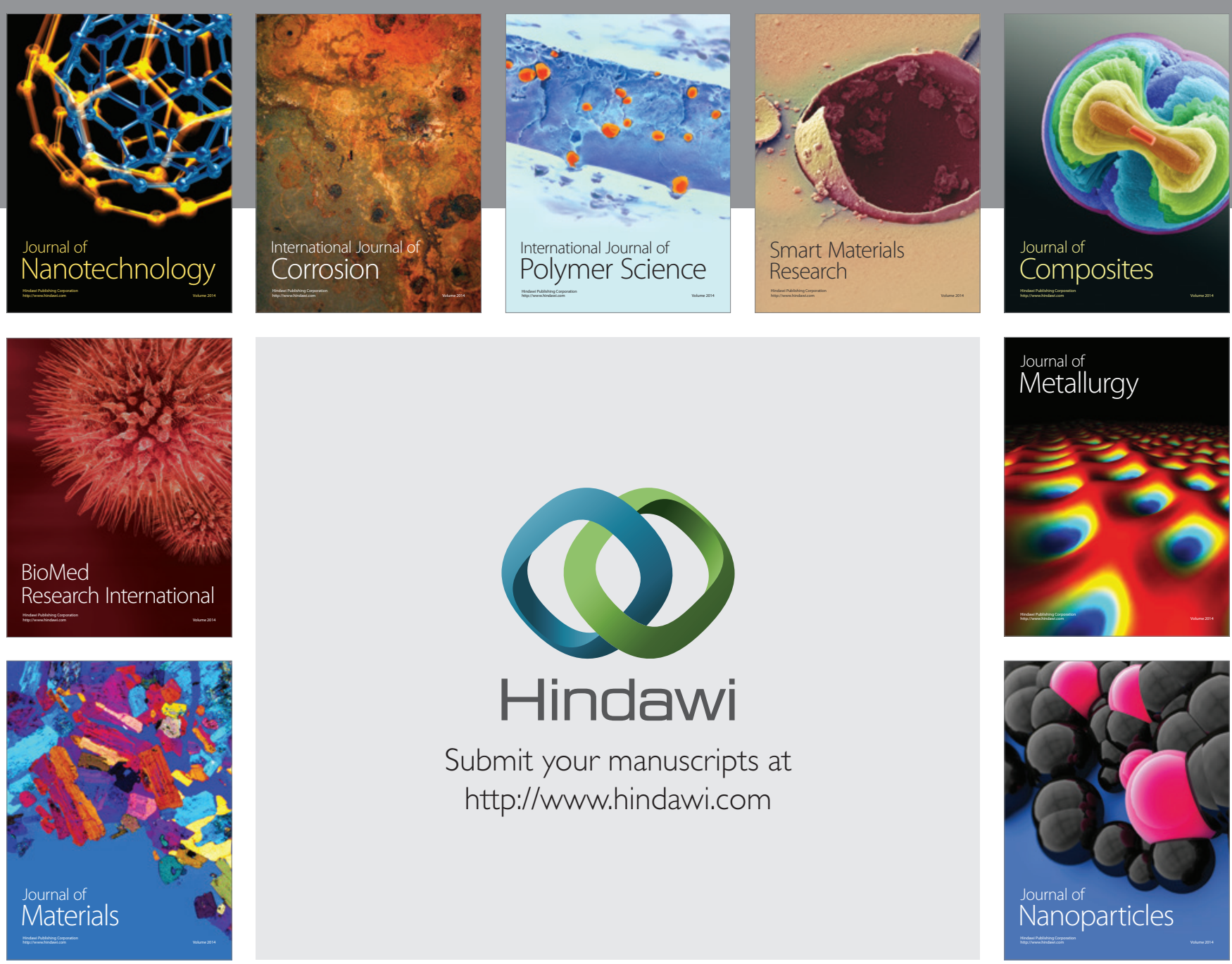

Submit your manuscripts at http://www.hindawi.com
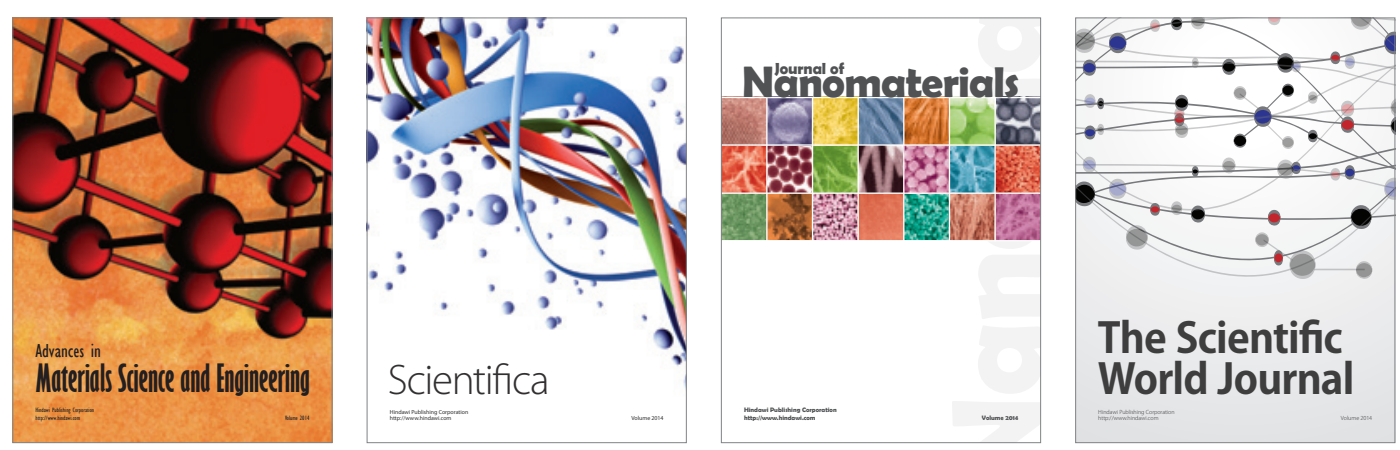

\section{The Scientific World Journal}
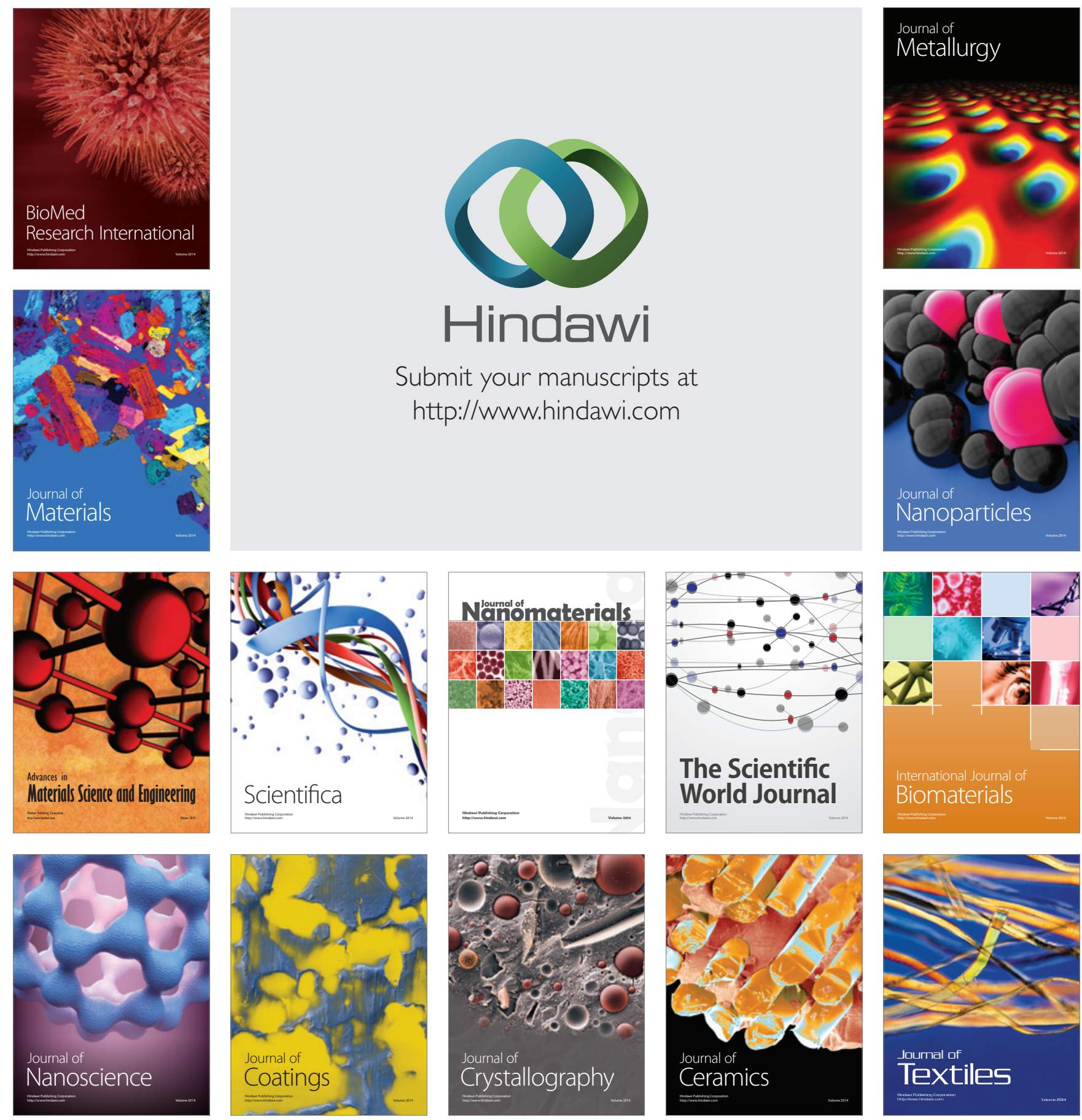